\title{
IDENTIFICATION AND PURIFICATION OF GLIAL GROWTH FACTOR ${ }^{1}$
}

\author{
GREG ERWIN LEMKE ${ }^{2}$ AND JEREMY P. BROCKES ${ }^{3}$ \\ Division of Biology 216-76, California Institute of Technology, Pasadena, California 91125
}

Received May 12, 1983; Accepted July 5, 1983

\begin{abstract}
Ahstract
Cultured rat Schwann cells are stimulated to divide by a protein growth factor, present in extracts of bovine brain and pituitary, which we have named glial growth factor (GGF). Two lines of evidence indicate that GGF activity in both brain and pituitary resides in a protein of $M_{\mathrm{r}}=31,000$. (1) Four independently isolated monoclonal antibodies that immunoprecipitate the activity react with an antigen of this molecular weight in sodium dodecyl sulfate (SDS)-polyacrylamide gels. (2) After SDS-polyacrylamide gel electrophoresis of partially purified preparations, mitogenic activity on Schwann cells is recovered at this molecular weight. GGF has been purified approximately $10^{5}$-fold to apparent homogeneity from bovine pituitary anterior lobes by a combination of column chromatography steps and preparative SDS gel electrophoresis. Purified human platelet-derived growth factor, a molecule with properties similar to those of GGF, is inactive on Schwann cells and therefore appears to be distinct.
\end{abstract}

The growth, division, and survival of animal cells in culture are dependent on the presence of growth factors and hormones. These molecules are often present in animal sera, tissue extracts, and other undefined medium supplements. For some cell types it has been possible to replace the general serum requirement with an appropriate mixture of purified growth factors (see, for example, Bottenstein et al., 1979). It has been suggested that the development of new cell culture systems will lead to the identification of new growth factors of biological significance (Ross and Sato, 1979).

We have described the use of immunological methods to obtain pure populations of rat Schwann cells from the neonatal sciatic nerve (Brockes et al., 1977, 1979). These cells divide very slowly in a conventional tissue culture medium containing $10 \%$ fetal calf serum, but they are strongly stimulated by an activity present in extracts of bovine brain and pituitary (Raff et al., 1978; Brockes et al., 1979). This activity is not detectable in extracts of

\footnotetext{
${ }^{1}$ We wish to thank Teresa Stevens for her skillful assistance with Schwann cell cultures. This work was supported in part by the National Institutes of Health (Grant NS 14403-05), the Kroc Foundation, and the Pew Memorial Trust.

' 'T'o whom correspondence should be addressed, at his present address: Institute of Cancer Research, College of Physicians and Surgeons, Columbia University, 701 West 168th Street, New York, NY 10032.

${ }^{3}$ Present address: MRC Cell Biophysics Unit, 26-29 Drury Lane, London WC2B-5RL, England.
}

non-neural tissue and is not mediated by a variety of purified growth factors and pituitary hormones (Raff et al., 1978). In a previous report (Brockes et al., 1980), the activity was partially purified from extracts of the bovine pituitary by a combination of cation exchange chromatography and gel filtration. The most purified fraction still displayed significant heterogeneity, but further electrophoretic analyses by native and sodium dodecyl sulfate (SDS) gels indicated that the activity was associated with a basic protein of $M_{\mathrm{r}}=30,000$ which readily dimerized. In addition to its action on Schwann cells, this molecule was active in stimulating division of cultured astrocytes of the rat corpus callosum and of fibroblasts, but not of oligodendrocytes and macrophage-like microglia (Brockes et al., 1980). We have also reported on the activity in bovine brain (Brockes and Lemke, 1981; Brockes et al., 1981) which exhibits a reproducible variation in specific activity between regions and which is indistinguishable from that of the pituitary by electrophoretic and chromatographic criteria. In view of its localization to the nervous system, and its action on Schwann cells and astrocytes, the molecule has been named glial growth factor (GGF).

In this paper we describe two new lines of evidence which substantiate our earlier identification of the active species. In addition, we describe a method which permits purification of GGF to apparent homogeneity and demonstrate its distinction from a previously characterized growth factor which is related in structure and function. 


\section{Materials and Methods}

Materials. Lyophilized bovine anterior lobes, rats, Schwann cell tissue culture media and plastics, and radioisotopes were all purchased as described previously (Brockes et al., 1980). Protein A was from Pharmacia and was iodinated according to the method of Moore et al. (1982). Hybridoma materials were prepared or purchased as described by Moore et al. (1982). NIH 3T3 cells were a gift of Dr. Rex Risser, University of Wisconsin, Madison. Purified human platelet-derived growth factor was a gift of Drs. Elaine Raines and Russell Ross, University of Washington, Seattle.

Cell culture. Rat Schwann cells were dissociated from neonatal sciatic nerve, purified by immunoselective methods, and maintained as described previously (Brockes et al., 1977, 1979, 1980). NIH 3T3 cells were maintained in Dulbecco's modified Eagle's medium (DMEM) with $10 \%$ fetal calf serum (FCS).

[ ${ }^{125}$ I]IUdR incorporation assay. The incorporation of $\left[{ }^{125} \mathrm{I}\right]$ iododeoxyuridine $\left(\left[{ }^{125} \mathrm{I}\right] \mathrm{IUdR}\right)$ into Schwann cells growing in microwells was determined as described previously (Brockes et al., 1980; Brockes and Lemke, 1981). For constructing dose response curves, the stimulation of $\left[{ }^{125} I\right] I U d R$ incorporation was plotted against the logarithm of protein concentration (see, for example, Figs. $4 D$ and 5). Stimulation of DNA synthesis in NIH 3T3 was determined as follows: cells were grown to confluence in microwells in DMEM $+10 \%$ FCS. The medium was then changed and the cells were maintained at confluence for an additional 4 to 5 days. Test solutions (diluted to an appropriate concentration in HEPES-buffered DMEM (HMEM) $+0.5 \mathrm{mg} / \mathrm{ml}$ of bovine serum albumin (BS $\Lambda$ ) were added for $48 \mathrm{hr}$, and [ $\left.{ }^{125} \mathrm{I}\right] \mathrm{IUdR}(2 \mu \mathrm{Ci} / \mathrm{ml})$ was added for the final 16 to $20 \mathrm{hr}$ of this period. The cells were then harvested with a multiple sample device and counted as described previously for the Schwann cell microwell assay (Brockes et al., 1980).

Monoclonal antibody methods. Female BALB/c mice were immunized with partially purified fractions of GGF complexed with poly(I):poly(C) as an adjuvant as described previously (Lemke and Brockes, 1981). Spleen cells from responding animals were fused to SP-2/0 myeloma cells as described by Moore et al. (1982). Culture supernatants from the resulting hybridomas were screened for GGF binding by assaying their ability to precipitate growth factor activity from solution as follows: $40 \mu \mathrm{l}$ of culture medium (or an appropriate dilution) were incubated with $10 \mu \mathrm{l}$ of CM-cellulose fraction GGF (Brockes et al., 1980) at $400 \mu \mathrm{g} / \mathrm{ml}$ for $4 \mathrm{hr}$ at $37^{\circ} \mathrm{C}$. Ten microliters of a solution of normal mouse IgG $(60 \mu \mathrm{g} / \mathrm{ml}$ in HMEM $+10 \%$ FCS) and $10 \mu \mathrm{l}$ of a solution of affinity purified rabbit anti-mouse IgG $(400 \mu \mathrm{g} / \mathrm{ml})$ were then added. The mixture was incubated at $37^{\circ} \mathrm{C}$ for $30 \mathrm{~min}$ and then overnight at $4^{\circ} \mathrm{C}$. After centrifugation at 20,000 $\times g$ for $4 \mathrm{~min}$ at $4^{\circ} \mathrm{C}, 20 \mu \mathrm{l}$ of the resulting supernatant were testcd in the microwell proliferation assay (see Lemke and Brockes, 1981).

Antibody reactions with partially purified GGF fractions resolved on SDS gels were performed essentially as described by Moore et al. (1982), except that anti-mouse $\lg G$ was not used and all reactions were carried out at
$\mathrm{pH} 8.5$ to permit ${ }^{125}$ I-protein A binding to monoclonal $\mathrm{IgG}_{1}$ antibody (Ey et al., 1978); anti-GGF antibody $\mathrm{E}$ $\mathrm{IgG}_{1}$ (purified to near homogeneity from ascites fluid by DEAE-cellulose chromatography) was used at $0.9 \mu \mathrm{g} / \mathrm{ml}$. Autoradiography was performed using Kokak XAR-5 xray film with an intensifying screen. Exposures were carried out at $-70^{\circ} \mathrm{C}$ for 18 to $28 \mathrm{hr}$.

Analytical SDS gel electrophoresis. Small-scale $(5.5 \times$ $7.0 \times 0.1 \mathrm{~cm}, 1.5-\mathrm{cm}$ stack) SDS gel electrophoresis was conducted according to the methods of Laemmli and Favre (1974), but with modified concentrations of bisacrylamide $(0.11 \%$ for $12.5 \%$ acrylamide gels and $0.09 \%$ for $15 \%$ acrylamide gels). Gels were stained either with $0.2 \%$ Coomassie blue (in $50 \%$ methanol, $10 \%$ acetic acid) or according to the silver staining procedure described by Morrissey (1981). Samples to be analyzed for migration of growth factor activity were solubilized in $0.5 \mathrm{vol}$ of sample buffer ( $80 \mathrm{~mm}$ Tris- $\mathrm{HCl}, \mathrm{pH} 6.8,10 \%$ glycerol, $2 \%$ SDS) by heating at $37^{\circ} \mathrm{C}$ for 2 to $3 \mathrm{~min}$ in the absence of disulfide reducing agent. After electrophoresis, the sample lane was excised from the gel and sliced into 2.5$\mathrm{mm}$ segments, and the segments were placed into sterile snap-cap tubes and washed with $1 \mathrm{ml}$ of sterile phosphate-buffered saline (PBS) for $30 \mathrm{~min}$ at room temperature by vigorous agitation. The PBS was replaced with $1 \mathrm{ml}$ of fresh buffer, and a second wash was performed for an additional $10 \mathrm{~min}$. The PBS was then removed and replaced with $150 \mu \mathrm{l}$ of HMEM containing $10 \%$ FCS. Proteins were eluted from the segments by shaking overnight at $4^{\circ} \mathrm{C}$. Fifteen to $20 \mu \mathrm{l}$ of each eluate were assyed in the standard microwell proliferation assay.

Large-scale purification of GGF. CM-cellulose fractions of GGF were prepared from 20,000 and 10,000 lyophilized anterior lobes as described previously (Brockes et al., 1980). In brief, tissue was extracted at $\mathrm{pH} 4.5$, fractionally precipitated with ammonium sulfate, and chromatographed through batch elution from CM-cellulose. This material was then processed in two alternative ways. In procedure I $(20,000$ lobes, starting material), the CMcellulose fraction was reapplied to a $200-\mathrm{ml} \mathrm{CM}$-cellulose column equilibrated with $0.1 \mathrm{M}$ sodium phosphate, $\mathrm{pH}$ 6.0 ( $\mathrm{P}$ buffer $)+0.025 \mathrm{M} \mathrm{NaCl}$, and then eluted with a 2 liter linear gradient from $0.025 \mathrm{M}$ to $0.210 \mathrm{M} \mathrm{NaCl}$ in $\mathrm{P}$ buffer. Active fractions (see Fig. $4 A$ ) were pooled (total volume $=550 \mathrm{ml}$ ), precipitated with $309 \mathrm{gm}$ of ammonium sulfate, resuspended in $\mathrm{P}$ buffer $+0.4 \mathrm{M} \mathrm{NaCl}$, and chromatographed on an AcA 44 Ultrogel column exactly as described previously (Brockes et al., 1980). Active fractions (see Fig. $4 B$ ) were pooled, applied to a $5.5-\mathrm{ml}$ column of phosphocellulose P11 equilibrated with $\mathrm{P}$ buffer $+0.4 \mathrm{M} \mathrm{NaCl}$, and then eluted with a 60 -ml linear gradient from $0.4 \mathrm{M}$ to $0.85 \mathrm{M} \mathrm{NaCl}$ in $\mathrm{P}$ buffer. GGF was purified from active fractions of the phosphocellulose elution by small-scale SDS gel electrophoresis and elution by the procedure of Mendel-Hartvig (1982). In procedure II $(10,000$ lobes, starting material), the CM-cellulose fraction (in $\mathrm{P}$ buffer $+0.35 \mathrm{M} \mathrm{NaCl}$ ) was applied directly to a 25-ml phosphocellulose column, equilibrated with $\mathrm{P}$ buffer $+0.35 \mathrm{M} \mathrm{NaCl}$, and then eluted with a 200-ml linear gradient from $0.35 \mathrm{M}$ to $0.85 \mathrm{M} \mathrm{NaCl}$, in $\mathrm{P}$ buffer. Active fractions from this run were pooled and concentrated to $3.5 \mathrm{mg} / \mathrm{ml}$ in an Amicon cell (total 
protein recovered $=35 \mathrm{mg}$ ). Six-milligram portions of this material were then purified by successive preparative gel electrophoreses under native and denaturing conditions. Native gel electrophoresis was performed in slab gels $(10 \mathrm{~cm} \times 12.5 \mathrm{~cm} \times 0.7 \mathrm{~cm}, 2.5$-cm stack) using the buffer system of Reisfeld et al. (1962), modified as described previously (Brockes et al., 1980). Samples were prepared by mixing them with $1 / 2 \mathrm{vol}$ of $1.5 \%$ agarose at $40^{\circ} \mathrm{C}$ for $1 \mathrm{~min}$, applied to a preformed well in the native stacking gel, and allowed to solidify. Electrophoresis was conducted at $50 \mathrm{~mA}$ at $4^{\circ} \mathrm{C}$ for approximately $7 \mathrm{hr}$, after which time a gel slice from 0.38 to 0.5 mobility relative to cytochrome $c$ was excised and cut into fine segments. The segments were placed in a $15-\mathrm{ml}$ tube with $5 \mathrm{ml}$ of $2 \times$ PBS and shaken $15 \mathrm{~min}$. The PBS was removed and $5 \mathrm{ml}$ of elution buffer (20 mM Tris-HCl, pH 6.8, $0.5 \%$ SDS) were added. Proteins were then eluted from the segments by shaking overnight at room temperature. The elution buffer was removed, an additional $5 \mathrm{ml}$ of buffer was added, and a second overnight elution was performed. The two eluates were pooled, lyophilized, and adjusted to approximately $2 \mathrm{ml}$ with distilled water. Glycerol was added to $10 \%$ final concentration, and the sample was heated to $37^{\circ} \mathrm{C}$ for 2 to $4 \mathrm{~min}$ before application to second-dimension SDS gels. Large-scale $(10 \mathrm{~cm}$ $\times 12.5 \mathrm{~cm} \times 0.5 \mathrm{~cm}, 12.5-\mathrm{cm}$ stack) SDS gel electrophoresis was carried out at room temperature at $25 \mathrm{~mA}$ for approximately $18 \mathrm{hr}$. Resolved proteins were visualized by staining the gel with Coomassie blue $(2 \%$ in $20 \mathrm{~mm}$ Tris- $\mathrm{HCl}, \mathrm{pH}$ 6.8) with several changes. The GGF band was identified by its migration relative to carbonic anhydrase and excised with a scalpel. The gel slice was incubated in SDS running buffer with $0.05 \%$ bromphenol blue for approximately $30 \mathrm{sec}$ and then positioned on top of a second SDS slab $(4 \mathrm{~cm} \times 12.5 \mathrm{~cm} \times 0.6 \mathrm{~cm})$ for electroelution exactly as described by Mendel-Hartvig (1982). Eluted proteins were collected in $80 \mathrm{~mm}$ Tris$\mathrm{HCl}, \mathrm{pH} 8.7,30 \%$ glycerol, $0.5 \%$ SDS.

\section{Results}

Molecular identification of GGF by monoclonal antibodies. Two new lines of evidence support our earlier tentative identification of GGF as a protein with an apparent $M_{\mathrm{r}}$ of 31,000 when analyzed by SDS gel electrophoresis (Brockes et al., 1980).

After immunizing with partially purified fractions from a large-scale purification of bovine pituitary GGF, we derived four mouse monoclonal antibodies apparently directed against this activity (Lemke and Brockes, 1981). An assay of one of these reagents (termed antibody ER) is shown in Figure 1. A partially purified fraction of GGF was incubated with culture medium from cells secreting $\mathrm{ER}$, and immune complexes were then precipitated after addition of an appropriate amount of anti-mouse IgG followed by centrifugation. The resulting supernatant was assayed for GGF activity in the standard Schwann cell proliferation assay. Immunoglobulin from clone ER but not clone 4-F7 produced a dose-dependent depletion of activity (Fig. 1). This depletion of activity was only demonstrable after indirect immunoprecipitation of immune complexes (Lemke and Brockes, 1981). The four independent clonal isolates that showed this reactivity

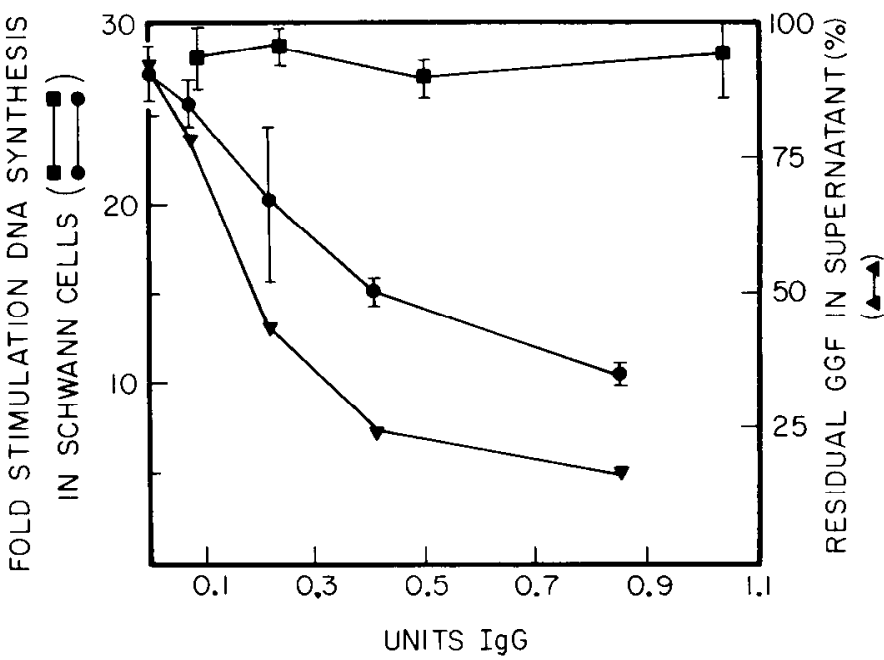

Figure 1. Titration of monoclonal anti-GGF. 4-F7 (a-m) is a hybridoma-secreting IgG that does not react with GGF, whereas antibody ER (-) does. Varying amounts of culture supernatants were incubated with the CM-cellulose fraction of GGF, followed by carrier mouse IgG and affinity purified rabbit anti-mouse IgG as described under "Materials and Methods." After centrifugation, the incubation mixtures were assayed for their ability to stimulate $\left[{ }^{125} \mathrm{I}\right] \mathrm{IUdR}$ incorporation into Schwann cells in the microwell assay. The depletion of GGF activity by antibody ER is corrected by the logarithmic doseresponse relationship (see Fig. $4 D$ ) to give the estimated amount of GGF protein remaining in solution $(\boldsymbol{\nabla}-\mathbf{\nabla})$. One unit of $\operatorname{IgG}$ is that present in $40 \mu \mathrm{l}$ of $4-\mathrm{F} 7$ culture supernatant as determined by a quantitative enzyme-linked immunosorbent assay procedure. The values for antibody $\mathrm{ER}$ are normalized to this. Each point represents the mean $\pm \mathrm{SD}$ of three microwell assays.

all secreted immunoglobulin of the $\operatorname{IgG}_{1}$ subclass as determined by Ouchterlony double diffusion analysis with subclass-specific antisera.

The antigen reactive with these reagents was investigated by running partially purified fractions of GGF on SDS gel electrophoresis and incubating with each of the monoclonal antibodies after the method of Burridge (1978). Bound $\operatorname{IgG}_{1}$ was detected by reaction with ${ }^{125} \mathrm{I}-$ labeled protein A at $\mathrm{pH} 8.5$ (Ey et al., 1978), followed by autoradiography. The results of such an experiment with antibody $\mathrm{E}$ are shown in Figure 2, $A$ and $B$. Although many protein species were detectable on the Coomassie blue-stained gel (Fig. $2 A$ ), the antibody reacted strongly and specifically with a single minor band of $M_{\mathrm{r}}=31,000$ (Fig. 2B). Each of the four independent monoclonal isolates reacted in the same way. There was evidence of very minor diffuse reactivity with protein species in the $M_{\mathrm{r}}=15,000$ to 30,000 range and at the dye front in some but not all preparations (see Fig. $2 B$ ), which may be a consequence of degradation. These antibodies also recognize a 31,000-dalton antigen in partially purified GGF preparations from bovine caudate nucleus and from whole chick brain (data not shown).

Molecular identification of GGF by SDS gel electrophoresis. We have found that GGF activity can be recovered from SDS gels run in the absence of disulfide reducing agents. Figure $3 A$ shows an experiment in which a partially purified preparation of GGF (phosphocellulose 
fraction 48; see Fig. $4 C$ ) was analyzed on a $12.5 \%$ SDS gel, using the standard Laemmli discontinuous buffer system. One lane was silver stained to detect proteins, and the other was sliced into segments which were washed in buffer and then eluted into tissue culture medium (see "Materials and Methods"). GGF activity was detected as a single peak of $M_{\mathrm{r}}=31,000$. No activity was recovered if the gels were run in the presence of disulfide reducing agents such as $2 \% \beta$-mercaptoethanol.

GGF activity is detectable in bovine brain (Raff et al., 1978 ) and shows a regional variation in specific activity with a particularly high level in the caudate nucleus (Brockes and Lemke, 1981; Brockes et al., 1981). The activity in the caudate is indistinguishable from that in the pituitary by the criteria of native gel electrophoresis at $\mathrm{pH} 4.5$ and ion exchange chromatography on phosphocellulose (Brockes and Lemke, 1981). When partially purified preparations of caudate GGF were analyzed by SDS gel electrophoresis, a major peak of activity was detected at 31,000 daltons (Fig. $3 B$ ). In addition, a minor

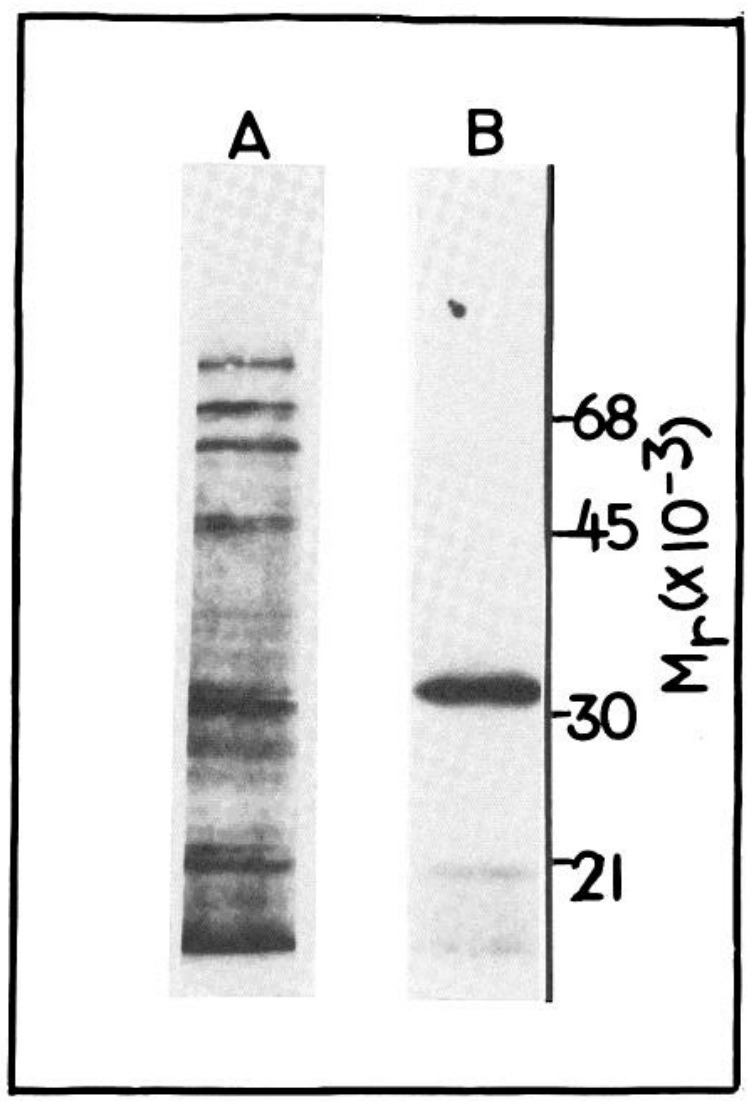

Figure 2. Analysis of the target antigen of monoclonal antiGGF by SDS gel electrophoresis. Forty-five micrograms of the CM-cellulose fraction of GGF (Brockes et al., 1980) were electrophoresed through a $15 \%$ SDS-polyacrylamide gel (see "Materils and Methods") in the presence of $2 \% \beta$-mercaptoethanol. The gel was reacted with antibody $\mathrm{E}$ and ${ }^{125} \mathrm{I}$-protein $\mathrm{A}$, stained with Coomassie blue, and then autoradiographed (overnight at $-70^{\circ} \mathrm{C}$ ) as described under "Materials and Methods." $A$ shows the proteins as visualized with Coomassie blue. $B$ is an autoradiogram of the same gel, showing the binding of antibody/ ${ }^{125} \mathrm{I}$-protein A at $M_{\mathrm{r}}=31,000$. peak of activity was detectable at 56,000 daltons in this experiment. This species, which constitutes less than $10 \%$ of the activity in the 31,000-dalton peak when corrected for the logarithmic dosage relationship (Lemke and Brockes, 1981; see Fig. 4D), has also been detected at low and variable levels in some less purified preparations of the pituitary activity. The existence of aggregates of the 31,000-dalton species is considered further under "Discussion."

Large-scale purification of bovine pituitary GGF. We have purified the 31,000-dalton species of GGF to apparent homogeneity by combining the previously described procedures of column chromatography and native gel electrophoresis (Brockes et al., 1980), together with a final step of preparative SDS gel electrophoresis. In the procedure outlined in Table I, the CM-cellulose fraction (see Brockes et al, 1980) from 20,000 lyophilized anterior lobes was further purified by gradient elution from CMcellulose (Fig. $4 A$ ), gel filtration on AcA 44 Ultrogel (Fig. $4 B$ ), and elution from phosphocellulose (Fig. 4C). Peak fractions from the phosphocellulose column gave plateau stimulation of Schwann cells at a concentration of 200 $\mathrm{ng} / \mathrm{ml}$ (Fig. $4 D$ ), indicating a purification factor of approximately 10,000 -fold with a yield of $3 \%$ (Table I). After SDS gel electrophoresis, approximately $10 \%$ of the protein (Fig. $4 D$ ) and all of the activity (Fig. $3 A$ ) resided in a 31,000-dalton band. This species could be further purified by preparative SDS gel electrophoresis followed by the elution procedure of Mendel-Hartvig (1982) (Fig. $4 D$ ), yielding approximately $4 \mu \mathrm{g} / 1,000$ anterior lobes.

In an alternative procedure which employs fewer steps, the CM-cellulose fraction (Brockes et al., 1980) from 10,000 anterior lobes was chromatographed on phosphocellulose essentially as in Figure $4 C$ and then was purified by preparative native gel electrophoresis at $\mathrm{pH} 4.5$ (Fig. $4 E$ ) using the buffer system of Reisfeld et al. (1962), as described earlier (Brockes et al., 1980). The pH 4.5 fractions were passively eluted from the gel slices and further purified by SDS gel electrophoresis to yield the 31,000-dalton species (Fig. $4 F$ ). The material resulting from this procedure (Fig. $4 F$ ) showed significant activity in the Schwann cell proliferation assay (after dilution into medium with $1 \mathrm{mg} / \mathrm{ml}$ of BSA and extensive dialysis to remove SDS), but at a concentration that was consistent with the loss of $95 \%$ of the activity due to the multiple electrophoretic steps.

Comparison with the platelet-derived growth factor (PDGF). PDGF has been purified from platelet lysates by virtue of its mitogenic effect on fibroblasts or 3T3 cells (Ross et al., 1979; Antoniades, 1981; Deuel et al., 1981; Heldin et al., 1981a). It shares several properties with GGF as defined in this paper and previously (Brockes and Lemke, 1981). Both are basic proteins of $M_{\mathrm{r}}=31,000$ that are functionally inactivated by disulfide reducing agents, are relatively heat stable, and act on fibroblasts. To further investigate their relationship, we assayed a preparation of purified human PDGF (Raines and Ross, 1982) for its ability to stimulate DNA synthesis in cultured rat Schwann cells. The preparation was active (Fig. 5) on mouse NIH 3T3 cells in the range of 1 to 20 $\mathrm{ng} / \mathrm{ml}$ as previously reported (Raines and Ross, 1982), but gave no significant stimulation of Schwann cells at 

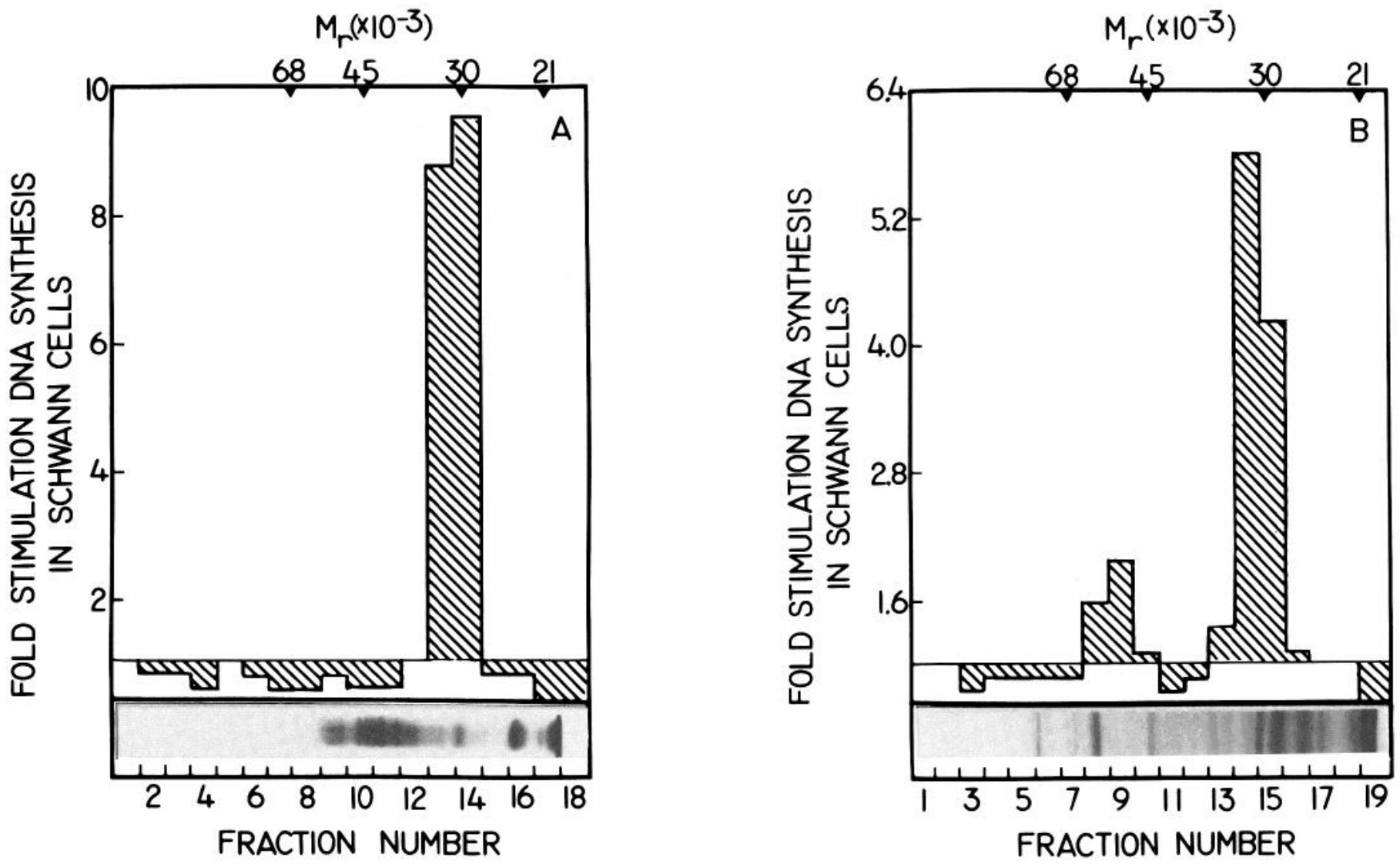

Figure 3. Identification of GGF activity after SDS-polyacrylamide gel electrophoresis. $A$, Electrophoresis in a $12.5 \%$ gel of approximately $1 \mu \mathrm{g}$ of a phosphocellulose fraction of GGF from the bovine pituitary ( $10 \%$ pure; see below). Samples were solubilized (without disulfide reduction) and electrophoresed as described under "Materials and Methods." The sample lane was excised and sliced into $2.5-\mathrm{mm}$ segments, and the proteins were eluted from each segment into medium (see "Materials nd Methods"). The GGF activity eluted from the gel slices was measured in the Schwann cell proliferation assay. The silver-stained profile of unreduced proteins and the migration of reduced molecular weight markers are from parallel lanes of the same gel. $B$, Electrophoresis in a $12.5 \%$ gel of $30 \mu \mathrm{g}$ of a phosphocellulose fraction of GGF prepared from the caudate nucleus of the bovine brain $(0.3 \%$ pure). Electrophoresis, elution of proteins, and analysis were as for $A$, except that the proteins were visualized with Coomassie blue.

these concentrations. A small but reproducible stimulation was observed at $100 \mathrm{ng} / \mathrm{ml}$. The Schwann cells used in these experiments were tested in parallel with the CM-cellulose fraction (Brockes et al., 1980) of GGF and were strongly stimulated with a normal dose response curve (Fig. 5).

\section{Discussion}

The two lines of evidence presented in this paper provide strong support for the identification of GGF activity with a 31,000 -dalton protein. Our earlier evidence for this was based on native gel electrophoresis of a partially purified preparation and was suggestive but not conclusive. The ability of a set of four monoclonal antibodies to both specifically precipitate GGF activity from solution and bind to the 31,000 -dalton species is independent evidence for the association of mitogenic activity with this molecule. It might still be argued, however, that GGF activity derives from a smaller component that is adventitiously associated with the 31,000 dalton protein. This possibility is made very unlikely by the demonstration that growth factor activity is re- covered at 31,000 daltons after denaturing electrophoresis in SDS.

Although we now consider this association to be established, the presence of oligomers is not fully understood. In previously reported gel filtration experiments (Brockes et al., 1980), the major peak of growth factor activity was observed to migrate with an apparent $M_{\mathrm{r}}$ of 56,000 (GGF dimer), whereas in procedure I, activity was observed predominantly at $M_{\mathrm{r}}=31,000$ (GGF monomer). We have found that the GGF dimer is largely removed as a result of the gradient elution from CM-cellulose of this latter procedure: if subjected to SDS gel electrophoresis under nonreducing conditions, material from pool $a$ (Fig. $4 A$ ) gives a major peak of activity at $M_{\mathrm{r}}=56,000$ (data not shown). Significant dimerization of GGF has not been detected in the more highly enriched fractions (AcA 44(Fig. 4B) and phosphocellulose P11 (Fig. 3A)) subsequently prepared from pool $b$ (Fig. $4 B$ ).

The two purification procedures that are reported above result in apparently homogeneous preparations of GGF, but ones whose bioactivity is significantly reduced after the preparative SDS electrophoresis steps. The 

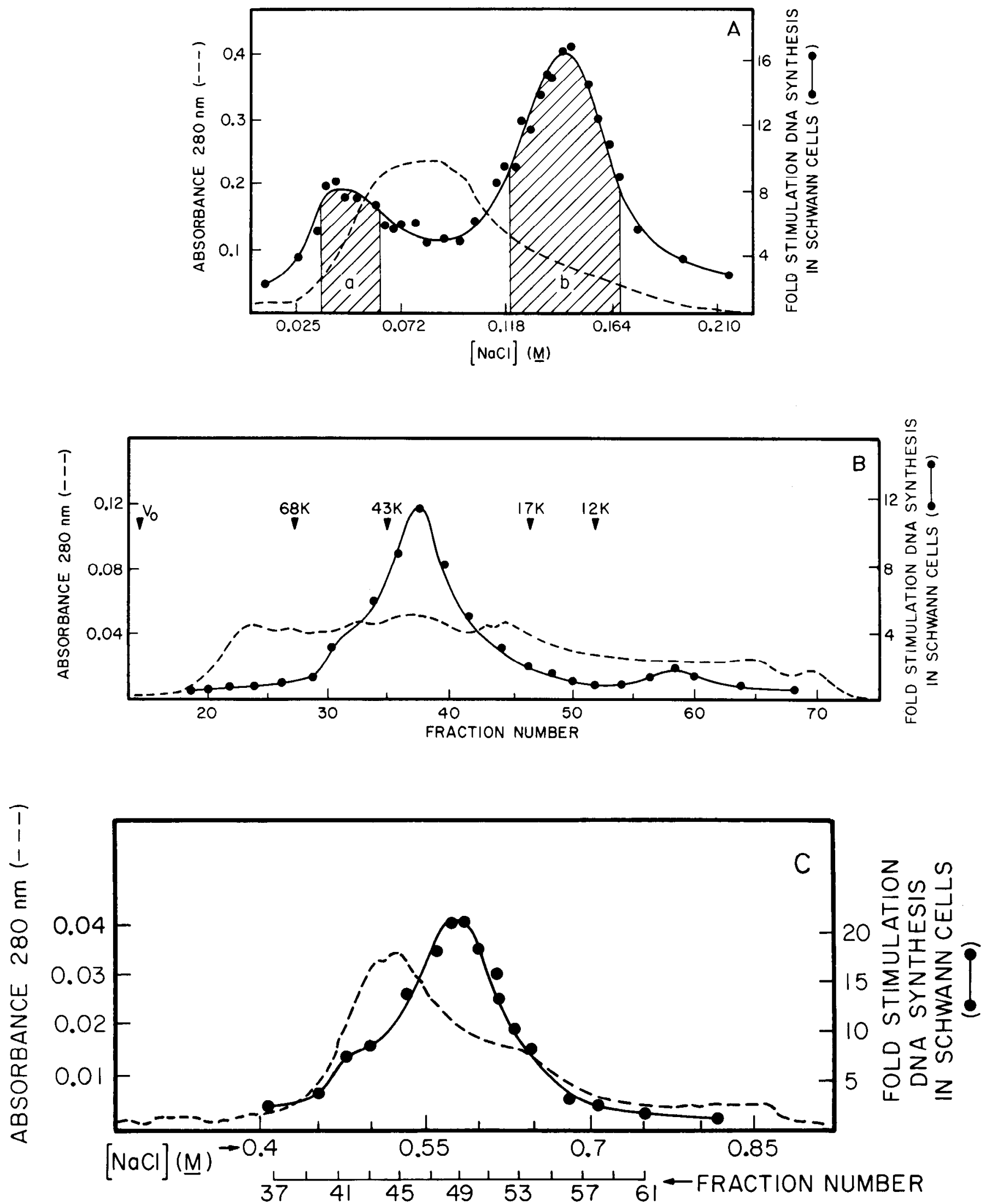

Figure 4. Steps in the large-scale purification of GGF. A, Gradient elution of the CM-cellulose fraction from CM-cellulose. The batch-eluted CM-cellulose fraction (1090 mg) was applied to a CM-cellulose column and eluted with a linear $\mathrm{NaCl}$ gradient as described under "Materials and Methods." Fractions were collected and assayed at $3 \mu \mathrm{g} / \mathrm{ml}$ in the Schwann cell proliferation assay. Two pools were made and pool $b$ was used for further purification (the properties of pool $a$ are considered under "Discussion"). B, Elution profile of the (gradient eluted) CM-cellulose fraction after gel filtration on AcA 44 Ultrogel. The CMcellulose fraction $(210 \mathrm{mg})$ was chromatographed on a calibrated column of AcA 44 as described under "Materials and Methods." 

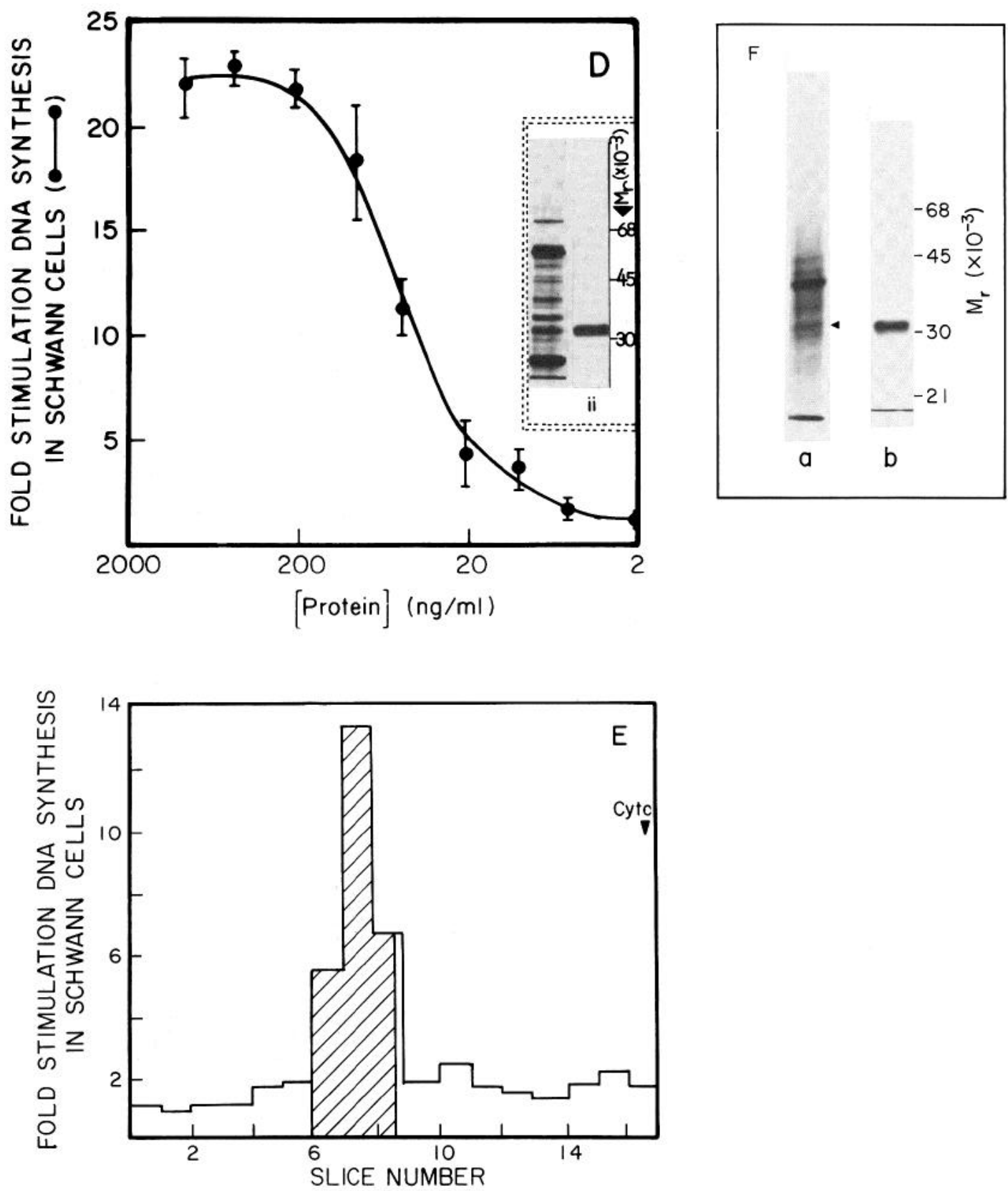

Figure 4, D-F

Fractions were collected and assayed at $0.5 \mu \mathrm{g} / \mathrm{ml}$. Fractions 36 to 40 were pooled for further purification. $C$, Elution profile of the AcA 44 fraction from phosphocellulose. The AcA 44 fraction (19 mg) was applied to a phosphocellulose column and eluted with a linear $\mathrm{NaCl}$ gradient as described under "Materials and Methods." Fractions were collected and assayed at $0.2 \mu \mathrm{g} / \mathrm{ml}$; no activity was detectable in the flow-through. $D$, Dose response curve and further purification of the phosphocellulose fraction. The phosphocellulose fraction (fraction 49 of $C$ ) was diluted in medium and assayed in the Schwann cell proliferation assay. Inset $i$, Proteins of this fraction $(1 \mu \mathrm{g})$ were analyzed on a $12.5 \%$ SDS gel followed by silver staining. The 31,000 -dalton GGF band accounts for approximately $10 \%$ of the protein as determined densitometrically, and can be purified to apparent homogeneity by excision from the gel and subsequent elution (see "Materials and Methods"). $i i$, Eluted material ( $0.1 \mu \mathrm{g})$ is shown after SDS gel electrophoresis followed by silver staining. $E$, Profile of phosphocellulose fractions after native gel electrophoresis at pH 4.5 . The phosphocellulose fraction $(6 \mathrm{mg})$, derived as described in the text, was subjected to polyacrylamide gel electrophoresis at pH 4.5 as described under "Materials and Methods." The migration of GGF activity relative to cytochrome $c$ was determined previously on pilot scale gels. A slice of $R_{\text {cytochrome } c}=0.38$ to 0.5 was excised and eluted as described under "Materials and Methods." A parallel lane of the pH 4.5 gel was sliced into $3-\mathrm{mm}$ segments which were eluted into medium and assayed in the Schwann cell proliferation assay. The activity profile in the parallel lane is shown together with the region (diagonally lined bar) excised from the sample lane. $F$, SDS gel electrophoresis. Shown in $a$ is the native gel eluate as resolved by electrophoresis through a preparative scale SDS-polyacrylamide slab gel (see "Materials and Methods"). The GGF band (arrowhead) was identified after staining with Coomassie blue by its migration to a position just above that for carbonic anhydrase. A gel slice containing this band was excised from the slab, and GGF was eluted according to the procedure of Mendel-Hartvig (1982). An analytical SDS gel of the eluted material $(0.2 \mu \mathrm{g})$ is shown in $b$. 
second procedure, which employs a combination of native gel electrophoresis at $\mathrm{pH} 4.5$ and SDS gel electrophoresis, is similar in design to that employed by Barde et al. (1982) in the isolation of a neurotrophic factor from pig brain and is a modification of the two-dimensional analytical procedure that we used previously (Brockes et al., 1980). Attempts to purify GGF by using the monoclonal antibodies as immobilized affinity reagents have thus far been largely unsuccessful. Although growth factor activity is purified approximately $10^{5}$-fold and the estimated potency of highly purified GGF is comparable to that of other purified mitogenic growth factors, it might still be formally argued that the final preparation of the 31,000dalton band is not homogeneous and contains one or more components of identical molecular weight which co-purify with GGF through the multiple steps of the purification procedures. For this reason, the homogeneity is termed "apparent." Amino acid sequence analysis of the purified preparation followed by the derivation of antisera to synthetic peptides, or the cloning and subsequent manipulation of the gene coding for this protein are clearly important elements of a definitive identification of the GGF molecule.

Although we have not undertaken an investigation of the mechanism of action of GGF at the cellular level, some of our data bear on this question. The equilibrium dissociation constant of the putative Schwann cell receptor for GGF can, for example, be estimated from the midpoint of dose response curves of highly purified fractions (such as the $10 \%$ pure preparation of Fig. $4 D$ ) to be approximately $10^{-10} \mathrm{M}$. This value is comparable to that exhibited by high affinity cell receptors for epidermal growth factor (Carpenter et al., 1975) and PDGF (Heldin et al., 1981b; Bowen-Pope and Ross, 1982), and

TABLE I

Summary of purification

The activity was purified from 20,000 lyophilized anterior lobes as described in the text. The fold purification through the phosphocellulose step was determined from the displacement of dose response curves (see Lemke and Brockes, 1981).

\begin{tabular}{lccc}
\hline \multicolumn{1}{c}{ Step } & $\begin{array}{c}\text { Total Protein } \\
(\mathrm{mg})\end{array}$ & $\begin{array}{c}\text { Recovery of } \\
\text { Activity (\%) }\end{array}$ & $\begin{array}{c}\text { Fold } \\
\text { Purification }\end{array}$ \\
\hline $\begin{array}{l}\text { Crude extract } \\
\text { Ammonium sulfate }\end{array}$ & $\begin{array}{c}400,000 \\
\quad 202,000\end{array}$ & 100 & 2 \\
$\quad \begin{array}{l}\text { fraction } \\
\text { CM-cellulose (batch } \\
\quad \text { elution) }\end{array}$ & $\begin{array}{c}1,200 \\
(110 \text { set aside) }\end{array}$ & 30 & 100 \\
$\begin{array}{l}\text { CM-cellulose (gradient } \\
\text { elution) }\end{array}$ & 210 & 15 & 250 \\
$\begin{array}{l}\text { AcA 44 Ultrogel gel fil- } \\
\text { tration }\end{array}$ & 19 & 6.8 & 1,250 \\
$\begin{array}{l}\text { Phosphocellulose } \\
\text { SDS gel electrophoresis }\end{array}$ & 1.1 & 3.1 & 10,000 \\
\hline
\end{tabular}

${ }^{a}$ This is an estimate based on protein recoveries (as determined by calibrated silver-stained gels) in small-scale elutions by the procedure of Mendel-Hartvig (1982).

${ }^{b}$ This is an estimate based on activity recoveries in small-scale elutions by the procedure described under "Materials and Methods" and illustrated in Figure 3.

${ }^{c}$ This figure is based on the observation that GGF accounts for $10 \%$ of the protein in the phosphocellulose fraction.

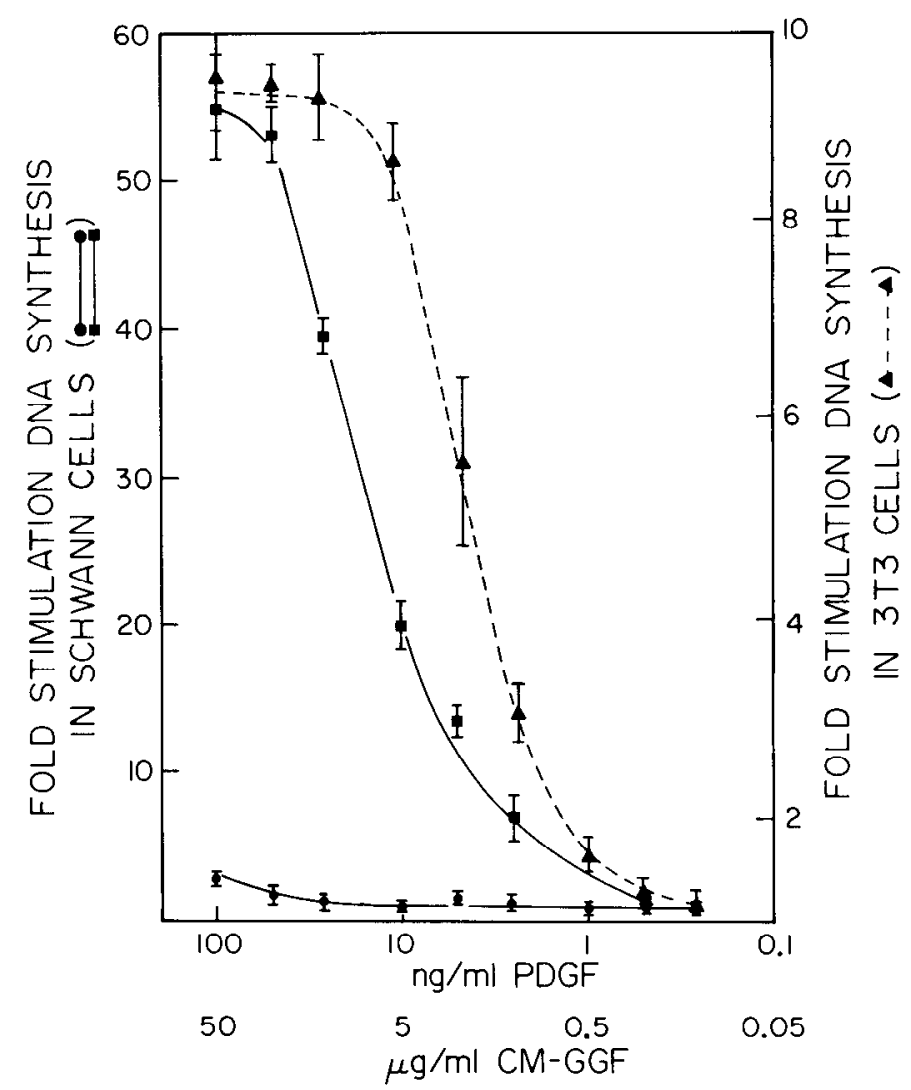

Figure 5. Comparison with PDGF. Purified human PDGF was diluted to varying concentrations with $\mathrm{HMEM}+0.5 \mathrm{mg} /$ $\mathrm{ml}$ of BSA and assayed for mitogenic activity simultaneously on both Schwann cells and NIH 3T3 fibroblsts. Proliferation assays were performed in microwells with $\left.{ }^{125} \mathrm{I}\right] \mathrm{IU} d \mathrm{dR}$ as label as described under "Materials and Methods." As a control, a CM-cellulose fraction of GGF was titered against the same batch of Schwann cells tested for PDGF response. Note that this is a relatively impure fraction of GGF. - GGF:Schwann cells; - PDGF:Schwann cells; $\mathbf{\nabla}-\mathbf{-}$, PDGF:3T3 cells.

indicates that GGF acts in a "hormonal" concentration range.

Although PDGF and GGF are strikingly similar, our results (Fig. 5) clearly demonstrate a functional disparity with respect to their action on Schwann cells. Additionally, GGF, unlike PDGF, appears to be a single polypeptide, in that treatment with disulfide reducing agents does not alter the observed molecular weight of the purified protein on SDS gels (data not shown) or the binding of anti-GGF antibodies to the 31,000-dalton antigen (Fig. 2). It seems possible, nevertheless, that these molecules are members of a family of growth factors, some of whose target cells (e.g., fibroblasts) overlap. The lack of effect of PDGF on Schwann cells is consistent with the relatively weak mitogenicity of $10 \%$ serum on these cells. It points to the importance of Schwann cell proliferation as a distinctive test for specific growth factors - in our studies we have found no defined mitogen other than GGF which stimulates their division. The relation of GGF to the cell surface mitogen of cultured neurites and central nervous system axolemma (Salzer and Bunge, 1980; De Vries et al., 1982) awaits chemical and immunochemical characterization of the latter. 
Although there is currently considerable interest in the mechanism of action of mitogenic growth factors at a molecular level, almost nothing is known about their significance in vivo. There is little information about their "endocrinology" in the sense of where they are made and released, or of the identity of their targets under circumstances of cell division in development and regeneration. The location of GGF in the nervous system and pituitary raises some possibilities as to its function which we have discussed elsewhere (Brockes and Lemke, 1981). It might be released from the pituitary as a circulating hormone. In addition, it may play a role in the control of glial cell division in development and after injury to the central and peripheral nervous systems. Finally, it might be important in that subset of neurotrophic phenomena which appears to reflect a mitogenic effect of nerves. As well as bovine brain and pituitary and rat pituitary (Raff et al., 1978), we have detected GGF activity on rat Schwann cells in chick, frog, newt, and axolotl brain (unpublished results). It has also been detected in the regeneration blastema of the axolotl, a context in which nerves appear to stimulate division of the progenitor cells of the regenerate (Singer, 1952). The chemical and immunochemical characterization reported in this paper is clearly a prerequisite for a critical evaluation of all these possibilities.

\section{References}

Antoniades, H. N. (1981) Human platelet-derived growth factor (PDGF): Purification of PDGF-I and PDGF-II and separation of their reduced subunits. Proc. Natl. Acad. Sci. U. S. A. 78: 7314-7317.

Barde, Y. -A, D. Edgar, and H. Thoenen (1982) Purification of a new neurotrophic factor from mammalian brain. EMBO J. 1: 549-553.

Bottenstein, J., I. Hayashi, S. Hutchings, H. Masui, J. Mather, D. B. McClure, S. Ohasa, A. Rizzino, G. Sato, G. Serrero, R. Wolfe, and R. Wu (1979) The growth of cells in serum-free hormone-supplemented media. Methods Enzymol. 58: 94109.

Bowen-Pope, D. F., and R. Ross (1982) Platelet-derived growth factor. II. Specific binding to cultured cells. J. Biol. Chem. 257: 5161-5171.

Brockes, J. P., and G. E. Lemke (1981) The neuron as a source of mitogen. In Development in the Nervous System, D. R. Garrod and J. D. Feldman, eds., pp. 309-327, Cambridge University Press, Cambridge, UK.

Brockes, J. P., K. L. Fields, and M. C. Raff (1977) A surface antigenic marker for rat Schwann cells. Nature 266: 364366.

Brockes, J. P., K. L. Fields, and M. C. Raff (1979) Studies on cultured rat Schwann cells. I. Establishment of purified populations from cultures of peripheral nerve. Brain Res. 165: $105-118$.

Brockes, J. P., G. E. Lemke, and D. R. Balzer (1980) Purification and preliminary characterization of glial growth factor from the hovine pituitary. J. Biol. Chem. 255: 8374-8377.

Brockes, J. P., K. J. Fryxell, and G. E. Lemke (1981) Studies on cultured Schwann cells. J. Exp. Biol. 95: 215-230.

Burridge, K. (1978) Direct identification of specific glycoproteins and antigens in SDS gels. Methods Enzymol. 50: 5465.
Carpenter, G., K. J. Lembach, M. M. Morrison, and S. Cohen (1975) Characterization of the binding of ${ }^{125}$ I-labeled epidermal growth factor to human fibroblasts. J. Biol. Chem. 250. 4297-4304.

Deuel, T. F., J. S. Huang, R. T. Proffitt, J. V. Baenziger, D. Chang, and B. B. Kennedy (1981) Human platelet-derived growth factor: Purification and resolution into two active protein fractions. J. Biol. Chem. 256: 8896-8899.

De Vries, G. H., J. L. Salzer, and R. P. Bunge (1982) Axolemma enriched fractions from the peripheral nervous system and central nervous system are mitogenic for cultured Schwann cells. Dev. Brain Res. 3: 295-299.

Ey, P. L., S. J. Prowse, and C. R. Jenkin (1978) Isolation of pure $\operatorname{IgG}_{1}, \operatorname{IgG}_{2 \mathrm{a}}$ and $\operatorname{IgG}_{2 \mathrm{~b}}$ immunoglobulins from mouse serum using protein A-Sepharose. Immunochemistry 15: 429-436.

Heldin, C. H., B. Westermark, and A. Wasteson (1981a) Platelet-derived growth factor: Isolation by a large-scale procedure and analysis of subunit composition. Biochem. J. 193: 907-913.

Heldin, C. -H., B. Westermark, nd A. Wasteson (1981b) Specific receptors for platelet-derived growth factor on cells derived from connective tissue and glia. Proc. Natl. Acad. Sci. U.S.A. 78: 3664-3668.

Laemmli, U. K., and M. Favre (1974) Maturation of the head of bacteriophage T4. J. Mol. Biol. 80: 575-599.

Lemke, G. E., and J. P. Brockes (1981) An immunochemical approach to the purification and characterization of glial growth factor. In Monoclonal Antibodies to Neural Antigens, R. McKay, M. C. Raff, and L. Reichardt, eds., pp. 133-140, Cold Spring Harbor Laboratory, Cold Spring Harbor, NY.

Mendel-Hartvig, I. (1982) A simple and rapid method for the isolation of peptides from SDS-containing gels. Anal. Biochem. 121: 215-217.

Moore, H. -P. H., L. C. Fritz, M. A. Raftery, and J. P. Brockes (1982) Isolation and characterization of a monoclonal antibody against the saxitoxin-binding component from the electric organ of the eel Electrophorus electricus. Proc. Natl. Acad. Sci. U.S.A. 79: 1673-1677.

Morrissey, J. H. (1981) Silver stain for protein in polyacrylamide gels. Anal. Biochem. 117: 307-310.

Raff, M. C., E. R. Abney, A. Hornby-Smith, and J. P. Brockes (1978) Schwann cell growth factors. Cell 15: 813-822.

Raines, E. W., and R. Ross (1982) Platelet-derived growth factor. I. High yield purification and evidence for multiple forms. J. Biol. Chem. 257: 5154-5160.

Reisfeld, R. A., U. J. Lewis, and D. E. Williams (1962) Disk electrophoresis of basic proteins and peptides on polyacrylamide gels. Nature 195: 281-283.

Ross, R., and G. H. Sato (1979) Cell culture and endocrinology: An overview. In Hormones and Cell Culture, G. H. Sato and R. Ross, eds., Vol. B, pp. 965-971, Cold Spring Harbor Laboratory, Cold Spring Harbor, New York.

Ross, R., A. Vogel, P. Davies, E. Raines, B. Karuja, M. J. Rivest, C. Gustafson, and J. Glomset (1979) The plateletderived growth factor. In Hormones and Cell Culture, G. H. Sato and R. Ross, eds., pp. 3-16, Cold Spring Harbor Laboratory, Cold Spring Harbor, NY.

Salzer, J. L., and R. P. Bunge (1980) Studies of Schwann cell proliferation. I. An analysis in tissue culture of proliferation during development, Wallerian degeneration, and direct injury. J. Cell Biol. 84: 739-752.

Singer, M. (1952) The influence of the nerve in regeneration of the amphibian extremity. Q. Rev. Biol. 27: 169-200. 